\title{
Chemistry of Soil Organic Matter
}

\author{
Michael H.B. Hayes, ${ }^{1)} \quad$ Tsung-Yao Tseng, ${ }^{2} \quad$ Ming-Kuang Wang, \\ 【Summary 】
}

Humic substances (HSs) are by far the most abundant of the organic components of nature, and are present in all soils and natural waters that contain organic matter. The more widely accepted values for organic carbon (OC) in soil organic matter (SOM) are in the range of $(14 \sim 15) \times 10^{17}$ g. On the basis of a value of $15 \times 10^{17} \mathrm{~g}$, then the pool of OC in SOM is (2.5 3.0)-times greater than that of the terrestrial biomass estimated to be ca $5.6 \times 10^{17} \mathrm{~g}$. However, in forest and grassland soils with adequate rainfall, the reserves are very much greater. In broad terms, the pool represents a steady state between the input of plant and animal debris from net primary production (NPP) and losses from biological transformations (soil respiration) of the order of $68 \times 10^{15} \mathrm{~g} \mathrm{y}^{-1}$.

The importance of the SOM to carbon sequestration and global warming, or the greenhouse effect, has recently been recognised. Soil management is important in relation to the role of soils as sources and sinks of $\mathrm{C}$, and hence it is important in terms of global warming issues.

Because of the abundances and roles of HSs in soil and aquatic environments, studies of their compositions and structures can be justified on the basis of scientific curiosity. In terms of practical considerations, such studies are fundamental to an understanding of the mechanisms of the multifarious roles that HSs have in the environment.

Key words: carbon sequestration, global warming, humic substances, soil organic matter.

Hayes MHB, Tseng TY, Wang MK. 2007. Chemistry of soil organic matter. Taiwan J For Sci 22(3):215-26.

\section{學術論述}

\section{土壤有機質化學}

Michael H.B. Hayes ${ }^{1)}$ 曾聰堯 $^{2)}$ 王明光
摘 要

\footnotetext{
${ }^{1)}$ Chemical and Environmental Sciences, University of Limerick, Limerick, Ireland. University of Limerick, South Circular Road, Limerick, Munster, Ireland. 愛爾蘭利默里克大學化學暨環境科學 系, 愛爾蘭蒙斯特省利默里克郡South Circular路利默里克大學。

2) School of Forestry and Resource Conservation, National Taiwan University, 1 Roosevelt Rd., Sec. 4, Taipei 10617, Taiwan. 國立台灣大學森林環境暨資源學系, 10617臺北市羅斯福路四段1號。

${ }^{3)}$ Department of Agricultural Chemistry, National Taiwan University, 1 Roosevelt Rd., Sec. 4, Taipei 10617, Taiwan. 國立台灣大學農化學系, 10617臺北市羅斯福路四段1號。

4) Corresponding author, e-mail:mkwang@ntu.edu.tw 通訊作者。

Received March 2007, Accepted May 2007.2007年3月送審 2007年5月通過。
} 
土壤及水體中均存有有機物質, 而腐植物質(humic substances, HSs)顯然是自然界有機化合物中 含量最豐富的物質。有機碳( organic carbon, OC)在土壤有機質(soil organic matter, SOM)中的含量被 廣泛接受的數值大約是 $(14 \sim 15) \times 10^{17} \mathrm{~g}$, 若以有機碳含量 $15 \times 10^{17} \mathrm{~g}$ 為基值, 則由土壤有機質 $(\mathrm{SOM})$ 所 估計之量約為由陸棲生物量(biomass)所估計之量 (大約 $5.6 \times 10^{17} \mathrm{~g}$ ) 的 $2.5 \sim 3$ 倍。然而在降雨量充足的森 林及草生地土壤中, 有機碳的蓄存量則更多。長期而言, 從動、植物殘骸而生成的淨初級生產量(net primary production, NPP)的輸入, 到生物轉化作用(土壤呼吸)的損失(輸出), 有機碳的蓄存量(估算)大 約在 $68 \times 10^{15} \mathrm{~g} \mathrm{y}^{-1}$, 呈現穩定狀態。

近年來, 土壤有機質 $(\mathrm{SOM})$ 與碳吸存(蓄存)、溫室暖化及溫室效應的關係再次被認同。土壤經營 管理在碳排放及吸存上扮演重要角色, 因此土壤經營管理在全球暖化議題上是一個重要的項目。

因為腐植物質在土壤及水體環境中豐富含量及其扮演的角色, 因此科學上探索腐植物質之組成與 結構有其重要性。在實際而長期的考量下, 這些研究是基於了解腐植物質在環境中的腐植化機制及其 多變的角色。

關鍵詞：碳吸存、全球暖化、腐植物質、土壤有機質。

Michael H.B. Hayes、曾聰堯、王明光。2007。土壤有機質化學。台灣林業科學22(3):215-26。

\section{INTRODUCTION}

In recent times, interest has refocused on soil organic matter (SOM) because of its importance in carbon sequestration in terms of climate change (Miller et al. 2004, Clapp et al. 2005). Humic substances (HSs), the most abundant components of SOM are defined as "a series of relatively high molecular weight, yellow to black colored substances formed by secondary synthesis reactions" (Aiken et al. 1985, Tate 1987, Senesi and Loffredo 1999, Hayes and Malcolm 2001).

\section{DEFINITIONS}

\section{Classical definitions}

In the classical definition the term "humus" refers to the components of SOM that have been transformed to the extent that they bear no morphological resemblance to the materials of origin. Hayes and Swift (1978) subdivided these 'humified' materials into: (1) amorphous, polymeric, brown-colored humic substances which are differentiated on the basis of solubility properties into humic acids (HAs), fulvic acids (FAs), and humins (HUs); and (2) compounds belonging to rec- ognizable classes, such as polysaccharides, polypeptides, altered lignins, etc. These can be synthesized by microorganisms or arise from modifications of similar compounds in the original debris.

The more-widely used definitions consider humic substances (HSs) to be "a series of relatively high molecular weight, yellow to black colored substances formed by secondary synthesis reactions" (Stevenson 1994), and "a category of naturally occurring, biogenic, heterogeneous organic substances that can generally be characterized as being yellow to black in colour, of high molecular weight, and refractory" (Aiken et al. 1985). These definitions are vague, and some of the statements are being questioned at the present time. Nonetheless, the subdivisions outlined are useful for operational purposes.

Humic acids (HAs) are the components of HSs which are soluble in basic media but precipitated in acidic media at $\mathrm{pH} 1$ (water chemists use $\mathrm{pH} 2$ as the cutoff, at which point effectively all of the perceptible components from soils are precipitated). Many 
non-humic materials (such as some proteins, for example) are precipitated under similar conditions. In the classical definitions fulvic acids (FAs) are the components of alkaline extracts that remain in solution after a medium is acidified. Clearly that fraction would also contain many of the components of humus that belong to recognizable classes as mentioned above. Hence the term "fulvic acid fraction" is used for materials that remain in solution in the acidified medium. FA fractions from which the standard and reference FAs of the International Humic Substances Society (IHSS) were obtained were passed onto XAD-8 ((poly) methylmethacrylate) resin (Swift 1996). Polar non-humic components (such as saccharides) are considered to pass through the resin, while FAs are retained by the resin. The materials that pass through the resin may be retained by XAD-4 (styrenedivinylbenzene); these are defined as XAD-4 acids (Clapp et al. 2005).

Humins (HU) is the component of HSs that is not soluble in aqueous media at any $\mathrm{pH}$ value. It is a major component of the soil humic fraction and represents more than $50 \%$ of the organic C (OC) of soil (Kononova 1966) and more than $70 \%$ of the OC in lithified sediments (Keil and Hedges 1995). It is often considered to be the component of HSs associated with mineral colloids that is not extracted in an aqueous base. However, lignin residues that have not been sufficiently oxidized to provide hydratable functionalities in basic media, as well as algenans, cutans, and suberans, can contribute to the humin fraction (Derenne and Largeau 2001). On the basis of considerations of solubility in aqueous media, any HSs material that is extracted in an organic solvent, after an exhaustive extraction, in an aqueous base can be a considered to be humin.

A case for "re-defininitions"
We consider that the broad classifications outlined above are too general. By definition, HSs do not include biomolecules such as peptides, sugars, nucleic acid residues, fats, etc., which can be sorbed onto or co-precipitated (at $\mathrm{pH} 1$ or 2) with HAs, and the more polar of these may also be present in the FAs fraction. Thus the classical definitions might more accurately refer to HAs and FAs fractions, and more-descriptive definitions (still based on procedures for the isolation and fractionation of HSs) sought for the true HAs and FAs. Details are given below about newer procedures for the isolation and the fractionation of HSs.

Humins should not be confused with insoluble OMs from residues that have not been transformed to HSs. Thus it is often considered to be the insoluble residues that are in intimate associations with the soil inorganic colloids.

\section{ASPECTS OF GENESIS}

Stevenson (1994) outlined 3 pathways for the formation of HSs. In 1, amino compounds from microbial synthesis react with modified lignins. In the second, polyphenols oxidized to quinones react with amino compounds, and in the third, reducing sugars react with amino compounds to synthesize complex dark-colored macromolecules. Two general synthesis processes are involved. One, the degradation process, involves modifications of relatively intractable plant components such as lignins, suberins, cutins, etc., and also includes microbial products such as paraffinic macromolecules in algae and plant cuticles, such as the enzymatic depolymerization by activated oxygen free radicals (e.g., superoxide radicals) of species such as lignins and tannins. Stevenson (1994) also indicated how microorganisms secrete oxidative enzymes that depolymerize plant polymers. 
Oxidative transformations give rise to a variety of reactive functionalities, especially carbonyl/carboxyl groups. In the case of lignin, for example, the unaltered parts are relatively non-polar (hydrophobic), while the oxidized segments are hydrophilic. Thus, transformed lignin is an amphiphile (with separate hydrophobic and hydrophilic parts) and can exhibit surface-active properties.

Zech et al. (1997) discussed modifications to plant residues during the humification process, and these, among other changes, include oxidation and transformation of lignin side chains, the demethylation of lignins, the removal of carbohydrate materials, and the conversion of catechol-like products to quinones.

The second, or abiotic condensation (AC) process, involves the complete breakdown of bonds linking the component molecules of biopolymers and the resynthesis of macromolecular products through interactions between reactive molecules. The third pathway of Stevenson (1994) is also an abiotic process. Reducing sugars released from plant and animal sources react with amino compounds (amino acids and peptides) also released in degradation processes. This process, known as the Maillard reaction, gives rise to macromolecular melanoidins. A brief relevant review of that process is given (Hayes and Swift 1978, Clapp et al. 2005).

\section{ISOLATION AND FRACTIONATION OF HUMIC SUBSTANCE \\ Isolation of humic substances from soil}

Traditionally, aqueous solvents are used for isolating HSs from soils. Some organic solvents can be applied, Hayes (1985) concluded that "good" organic solvents have electrostatic factor (or the product of the relative permittivity and dipole moment) values exceeding 140 and $\mathrm{pK}_{\mathrm{HB}}$ (a measure of the strength of the solvent as an acceptor in hydrogen bonding) values of $>2$. Dimethyl formamide (DMF) and dimethyl sulfoxide (DMSO) meet these requirements, but there are problems with the recoveries of conventional fractions of HSs from these solvents. Hayes also discussed solubility parameter data to explain differences in the abilities of organic solvents to solvate HSs. The best of these solvents for $\mathrm{H}^{+}$-HAs have $\mathrm{d}_{p}$ (dispersion force), $\mathrm{d}_{h}$ (hydrogen bonding), and $\mathrm{d}_{b}$ (proton acceptor) values exceeding 6, 5, and 5 , respectively. Solvation is greatest when the product $\mathrm{d}_{a}$ (solvent) $\times \mathrm{d}_{b}$ (solute), or vice versa, is greatest. Water has large values for $\mathrm{d}_{h}, \mathrm{~d}_{a}$, and $\mathrm{d}_{b}$, which reflect the extents of its self-association because of hydrogen bonding. It follows that the $\mathrm{d}_{a}$ and $\mathrm{d}_{b}$ values of $\mathrm{H}^{+}$HAs are not sufficient to disrupt the attractive forces. Although water satisfies all of these criteria, it is a poor solvent for $\mathrm{H}^{+}$- and divalent- and polyvalent cation-exchanged HAs.

Standard isolation processes use water as the solvent. These involve extraction in basic and neutral salt solutions using, for example, $0.1 \mathrm{M} \mathrm{NaOH}$ after the sample is $\mathrm{H}^{+}$ion exchanged, usually with $\mathrm{HCl}$ (up to $1 \mathrm{M}$ ), or when not $\mathrm{H}^{+}$-exchanged, 0.1 $\mathrm{M} \mathrm{NaOH}+$ $0.1 \mathrm{M}$ sodium pyrophosphate $\left(\mathrm{Na}_{4} \mathrm{P}_{2} \mathrm{O}_{7}\right.$, Pyro $)$ is used. The acid treatment displaces chargeneutralizing cations, and the acidic functionalities in the $\mathrm{H}^{+}$-exchange system dissociate when the $\mathrm{pH}$ is raised above the $\mathrm{pK}_{\mathrm{a}}$ of the functionalities. Then the conjugate bases solvate in water. Neutralization with $\mathrm{H}_{3} \mathrm{PO}_{4}$, which serves as a neutral salt capable of complexing divalent and polyvalent metals, gives rise to inter- or intramolecular bridging effects that render the HSs insoluble in water. These metals are exchanged for $\mathrm{Na}^{+}$, and the $\mathrm{Na}^{+}$-carboxylates are solvated. However, HSs with low carboxyl charge densities will not dissolve, but will do so at higher $\mathrm{pH}$ values 
should sufficient phenolic functionalities be contained in the humic molecules. $\mathrm{Na}^{+}$-Pyro, at $0.1 \mathrm{M}$, has a $\mathrm{pH}$ value of 10.6 , and the $\mathrm{pK}_{\mathrm{a}}$ values of the phenolic functionalities are in the range of 8 to 10 . Weaker acidic functionalities, such as enols, contribute to the isolates at $\mathrm{pH}$ 12.6. Principles involved in the solvation processes are discussed in detail by Hayes (1985) and Clapp et al. (2005).

Hayes (2006) referred to $0.1 \mathrm{M} \mathrm{NaOH}+$ $6 \mathrm{M}$ urea for exhaustive extractions following extraction with $0.1 \mathrm{M} \mathrm{NaOH}$. The compositions of the isolates were broadly similar to those isolated at $\mathrm{pH} 12.6$, indicating that the urea may have liberated humic materials trapped within or hydrogen-bonded to the humin matrix. Hayes et al. (1996) carried out exhaustive and sequential extractions using distilled water, Pyro. at $\mathrm{pH}$ 7, Pyro. at $\mathrm{pH}$ 10.6, and Pyro. + 0.1 M NaOH.

Recently, Hayes (2006) referred to the use of DMSO $+6 \%$ concentrated $\mathrm{H}_{2} \mathrm{SO}_{4}$ following extraction with $\mathrm{NaOH}+$ urea. The extract in that instance significantly differed from prior extracts (Simpson et al. 2006).

The procedure used to isolate the standards of the IHSS employs a $0.1 \mathrm{M} \mathrm{HCl} / 0.3$ $\mathrm{M}$ HF treatment to remove finely divided inorganic soil colloids, and thereby provide materials with acceptable ash contents (Swift 1996). $\mathrm{HCl} / \mathrm{HF}$ treatment is repeated as often as necessary to lower the ash content to $<1 \%$. This treatment, followed by dialysis, leads to considerable losses of the humic fractions. Clapp and Hayes (1996) and Hayes et al. (1996) found that filtration through partially clogged 0.45 - or $0.2-\mu \mathrm{m}$ filters effectively lowered the ash contents of the fractions, and of course this procedure avoids degradation of HSs.

\section{Fractionation of HSs in the soil}

Uses are made of polarity, solubility, molecular size, and charge density differences for the fractionation of HSs. In principle, humic fractions that have weakly dissociable acids should be the first to precipitate as the $\mathrm{pH}$ is lowered, and the strongest acids would be last. Uses can be made of salts to give 'salting in' and 'salting out' effects, and of poor solvents such as ethanol and methanol to fractionally precipitate HAs from alkaline solutions.

A procedure, based on that of Malcolm and MacCarthy (1992), sufficiently dilutes SOM extracts (50 100 ppm) so that the DOM stays in solution when the $\mathrm{pH}$ is adjusted to 2 (dilution to $<50 \mathrm{ppm}$ is preferable). This solution is passed onto XAD-8 ((poly) methylmethacrylate) and XAD-4 (styrenedivinylbenzene) resins in tandem (packed in $0.01 \mathrm{M}$ acid). After back-elution with dilute $\mathrm{NaOH}$, the HAs are precipitated at $\mathrm{pH} 1$ and separated from the FAs. Hayes et al. (1996) modified this approach and exhaustively extracted with 1 solvent before proceeding to the next in the series: water; 0.1 M Pyro at $\mathrm{pH} 7.0 ; 0.1$ M Pyro at $\mathrm{pH} 10.6$; and $0.1 \mathrm{M} \mathrm{NaOH}+0.1 \mathrm{M}$ Pyro at $\mathrm{pH}$ 12.6. In this approach, the combined extracts (for each solvent system) are diluted to $<30 \mathrm{ppm}$, pressure-filtered through $0.2 \mu \mathrm{m}$ pore size filters, the $\mathrm{pH}$ adjusted to 2 , and the solutions passed through XAD- 8 and XAD-4 resins in tandem. The more-hydrophobic components, retained by the XAD-8 resin, are back-eluted in $0.1 \mathrm{M} \mathrm{NaOH}$, and the $\mathrm{pH}$ of the centre cut is adjusted to 1 (using $6 \mathrm{M} \mathrm{HCl})$.

Precipitation of the HAs is allowed to take place overnight at $4{ }^{\circ} \mathrm{C}$. After centrifugation, the FAs are desalted by passing them onto an XAD-8 resin, then passing distilled water through it until the conductivity is $<$ $100 \mathrm{~S} \mathrm{~cm}^{-1}$, back-eluting with $0.1 \mathrm{M} \mathrm{NaOH}$, passing the eluate slowly through an IR-120 $\left(\mathrm{H}^{+}\right.$-exchanged, sulphonated polystyrene) 
resin column, and finally freeze-drying. To desalt the HAs, the solution is dialyzed against distilled water until the dialysate is chloride free, and then it is freeze-dried. Alternatively, the HAs may be dissolved in a base and diluted until the concentration is $<$ $30 \mathrm{ppm}$. The $\mathrm{pH}$ of the solution is adjusted to 2, it is passed slowly onto XAD-8 (in $0.01 \mathrm{M}$ $\mathrm{HCl})$ resin and treated as for the FAs. Hayes et al. (1996) observed that in some instances, precipitates were formed in the $\mathrm{pH} 2.5$ to 2.0 range, and the compositions of these precipitates significantly differed from the HAs isolated from the XAD-8 resin (Hayes et al. 1996). XAD-4 acids cannot be considered to be valid components of HSs. These would be components of the HAs and FAs in the classical definitions, but should be regarded as non-humic materials in associations with the true humics in the operational definitions. We have observed that hydrocarbon-, fatty acid-, and wax-type materials are sorbed onto the cellulose acetate membrane during the filtration process, and these would also normally be included with the humic (HAs) fractions in the classical operational definition.

\section{WHAT IS MEANT BY COMPOSITION AND STRCTURES?}

In the humic sciences, composition refers to the functionalities and to the component molecules. In the classical chemical sense, structures of macromolecules include the size and shape, the sequences in which component molecules are linked, and the nature of the linkages, i.e., the associations between molecules that comprise their structures.

Analytical data are most meaningful when the samples analysed and compared have been subjected to the same isolation and fractionation procedures. A set isolation and fractionation procedure was followed during the isolation of IHSS standards (Swift 1996).
However, additional fractionations based on the charge density and size differences give subfractions with different compositions.

Swift (1996) updated the wet chemical and some spectroscopic procedures for determining of functional groups of HSs, and procedures are given in IHSS publications (Aiken et al. 1985, Hayes et al. 1989).

Although HSs are heterogeneous mixtures, the evidence suggests that substances from the same soil types and formed under the same environmental conditions are broadly similar. Nevertheless, it is unlikely that any 2 true humic molecules even in the same batch are exactly the same should the molecules have molecular weight (MW) values of even 3000 Da. However, distinct compositional differences can be expected between different fractions (HAs/FAs/humins) isolated from the same humic source, and strong differences may be observed between the humic fractions from different sources, soil types, and climates. Some general reactivities, regardless of source, will likely be broadly similar.

There is disagreement about the extents to which HSs can be considered to be macromolecular. Macromolecularity can, to some extent at least, be determined by the degree to which there are, if any, covalent links between HS molecules and peptides and oligoand polysaccharides. Should there be close associations between these biological molecules and HSs (and there are sufficient interactive functionalities in all of these molecules to allow such interactions to take place), then the sugars and peptides can be considered to be akin to prostethic groups of proteins.

\section{SIZES AND SHAPES OF HUMIC MOL- ECULES}

The classical concepts regard HSs as macromolecles with molecular weight values up to $1.5 \times 10^{6}$ Da (Hayes and Swift 1978). 
However, a second concept suggests that HSs are only pseudomacromolecles, and the macromolecular-like properties arise from associations of smaller molecular species in micellar or pseudomicellar structures, or through other forms of molecular associations possibly involving non-polar molecules such as long-chain hydrocarbons, fatty acids/esters/suberin-type, lipoprotein, components.

The different arguments with regard to sizes and shapes of humic molecules are dealt with in detail by Clapp et al. (2005). Considerations are given to the concept of HSs as micellar structures, and considerations of the micellar-type associations of humic molecules have considerable support. Micelle formation requires HSs to have amphiphilic properties wherein molecules have hydrophobic (nonpolar) and hydrophilic (polar) parts. At low concentrations, amphiphilic molecules exist solely as single unit species, but at concentrations above the so-called critical micelle concentration (CMC), or the concentration above which a surfactant molecule in solution will form an ordered aggregate or micelle, these will form compact, ordered aggregates or micelles. In micelles the hydrophobic groups are orientated towards each other and the interior, and the hydrophilic functionalities are on the outside. In special cases, polar groups can be found on the inside, and in such circumstances, interactions between these, such as hydrogen bonding, will decrease the hydrophilic character of the polar groups. Also the hydrophilic groups (inside or outside) in the micellar structures can interact through hydrogen bonding and dipole-dipole interactions with the solvent, water. Entropy increases as the water structure is disrupted and decreases with micelle formation. There is, however, a favorable increase in energy when roughly spherical micelles are formed (with the radius approximately equivalent to the length of the hydrophobic group in linear surfactants) at solution concentrations $<10$ times the CMC. Non-spherical micelles can form at higher concentrations. The free energy of the system increases when the structure of the solvent is disrupted during the addition of the surfaceactive materials. This increase is minimized when the molecules are concentrated at the surface and are oriented so that their hydrophobic groups are directed away from the liquid.

The micelle and hydrogen bonding concepts are, of course, forms of molecular associations. The micelle concept also includes hydrophobic bonding through associations of the non-polar functionalities.

\section{COMPOSITIONS OF HUMIC SUB- STANCES \\ Information from chemical degradation procedures}

Arguably, chemical degradation procedures (Hayes et al. 1989, Clapp et al. 2005) and nuclear magnetic resonance (NMR) provide the most useful information about the molecules that compose HSs.

The components of biological polymers have labile linkages that are readily hydrolysed. Although the information we have indicates that the molecular components or 'building blocks' of HSs are relatively simple, these molecules or units are linked by bonds that are, for the most part, difficult to cleave. For example, the "backbone" structures, or the major compositional units are linked by carbon-carbon bonds, by either linkages, or by other types of linkages that are degraded only when high inputs of energy are used. Up to $50 \%$ of the masses of soil HAs can be lost as $\mathrm{CO}_{2}$ (Hayes et al. 1989), especially from activated carboxyl groups, such as ketone acids, from hydroxybenzenecarboxylic acids, and as soluble molecules (e.g., sugars, 
amino acids, small amounts of purine and pyrimidine bases, and phenolic substances). These estimates were made for HAs fractions, which of course have saccharide and peptide materials especially associated with HAs. The total acidities of soil HAs are not decreased by hydrolysis because other acid groups are formed (e.g., from esters and lactones).

Hayes and Swift $(1978,1990)$ and Clapp et al. (2005) compiled a list of more than 100 products that have been identified in the digests of a variety of oxidative chemical degradations of HSs. Many additional products have been identified in the digests of reductive degradation procedures and as pyrolysis products in pyrolysis/gas chromatography/mass spectrometry (Pyr/GC/MS) degradation studies. At one time it was considered that the digest products were "building blocks" of humic macromolecules, but Hayes and Swift $(1978,1990)$ took into account the mechanisms involved in the degradation by the different chemical reagents and showed that 1 parent compound in the macromolecule can give rise to several digested products. The products depend on the type and concentration of reagent, the temperature, the reaction time, and so on. Most of the compounds identified in oxidative degradations are acids, as would be expected on the basis of mechanistic considerations. The aromatic acids range from benzenedi- to benzehexacarboxylic acids, and there is abundant evidence for monoto tri-hydroxy (or methoxy), and hydrocarbon substituents on the aromatic rings.

Fused aromatic structures are major digest products in zinc dust distillation and fusion reactions, and some of these have heterocyclic $\mathrm{N}$ digest products as listed by Hayes and Swift (1978), Stevenson (1994), and Clapp et al. (2005). Concepts of the structures of HSs were influenced for a time after such structures were identified in digests.
The abundance of benzenecarboxylic acids in the digests of alkaline permanganate oxidative degradations can, of course, arise from oxidations of fused aromatic components. It is now agreed that these may be artefacts. In the context of oxidative degradation, alkaline cupric oxide does not degrade fused aromatic structures to benzene polycarboxylic acids, and because these acids are contained in considerable abundances in the alkaline cupric oxide digests of HSs, it is not likely that fused aromatic structures can be considered to contribute to any significant extent to humic structures. However, these could arise from partially associated char materials that behave like HSs. Carbonylation reactions can produce benzenecarboxylic acids, and this possibility has not been resolved for the alkaline degradations of HSs.

Aliphatic dicarboxylic acids, ranging from ethanedioic to decanedioic, are abundant in oxidative digests, and there is also evidence for aliphatic tricarboxylic acids. Carboxyls could arise from cleavages of unsaturated groups in aliphatic chains and could also form from oxidizable functionalities, such as alcohols and aldehydes. Inevitably some are indigenous to the aliphatic structures (Clapp et al. 2005).

Sodium sulphide at elevated temperatures is used for the delignification of wood, Hayes and Swift (1968) devised a procedure for degradation of HSs using a saturated solution $(10 \%)$ of $\mathrm{Na}_{2} \mathrm{~S}$ at $250^{\circ} \mathrm{C}$ in an autoclave, by mechanisms outlined in Hayes et al. (1989). The aromatic compounds identified variously had 1 or 2 methoxy substituents (hydroxyl would have been converted to methoxyl in the methylation process needed for analysis by GC-MS), 1 or 2 methyls or other aliphatic substituents, and with the exception of phthalic acid, there is never more than 1 carboxyl group attached to the benzene nucle- 
us. This contrasts with benzenepolycarboxylic acids found in digests in which permanganate and alkaline cupric oxide are used.

\section{Information from pyrolysis}

There are increasing uses of pyrolysis (Pyr) procedures for studying the component molecules of HSs. Because of the large energy inputs in Pyr processes, most of the components of pyrolyzed macromolecules are drastically altered. Hence, awareness of the types of structures which can give rise to pyrolyzate products is essential for making plausible predictions of their structures. Pyrolyzates of soil HSs yield compounds indicative of origins in carbohydrates, polypeptides, lignins, polyphenols, and fatty acids and esters products, with likely origins in lignins and in microbially synthesized polyphenol substances.

\section{Information from spectroscopic proce- dures}

Considerations of spectroscopic procedures are given in Aiken et al. (1985), Hayes et al. (1989), and Clapp et al. (2005).

Nuclear magnetic resonance (NMR) is now a powerful spectroscopic technique which provides information about functionalities. Significant progress has been made since techniques such as multiple-pulse Fourier-transformation NMR, dipolar decoupling, cross-polarization nuclear induction spectroscopy, and cross-polarization magicangle spinning (CPMAS), direct polarization (DP) NMR, and dipolar dephasing (DD), and chemical shift anisotropic (CSA) techniques were introduced. These techniques enable better assignments of functional groups and allow some degree of quantification to be achieved.

Solid-state NMR has greatly contributed to our understanding of the compositions of
HSs. Resonance bands in the 10 45 (alkyl C), 45 65 (O-alkyl), 65 110 (ethers, hydroxyls, sugars), 110 140 (aromatic C), 140 160 (phenols, O-aryl), 160 190 (carboxyl, esters, amides), and 190 220 ppm (carbonyl of aldehydes, ketones) bands allow predictions to be made about the functionalities of humic components. Application of DD spectroscopy allows predictions of the extents of aromatic substitutions, and highlights methyl functionalities (including O-methyl). The CSA process suppresses aromatic functionalities and clearly distinguishes the aromatic $\mathrm{C}$ (with resonance at $105 \mathrm{ppm}$ ).

The development of high field magnets (of 500, 600, and $800 \mathrm{MHz}$ ) and multidimensional experiments has enabled liquidstate NMR to solve the problems associated with overlap in 1-dimensional (1D) spectra. Proton NMR ( ${ }^{1} \mathrm{H}$ NMR) in combination with ${ }^{13} \mathrm{C}$ NMR in $2 \mathrm{D}{ }^{1} \mathrm{H}-{ }^{13} \mathrm{C}$ heteronuclear multiple quantum coherence (HMQC) and heteronuclear multiple bond coherence (HMBC) correlation techniques; correlation spectroscopy (COSY); 2D homonuclear hartmann hahn (HOHAHA); total correlation spectroscopy; and rotating frame overhauser enhancement spectroscopy (ROESY) or nuclear overhauser effect spectroscopy (NOESY), and diffusion ordered spectroscopy (DOSY) have allowed considerable detail to be obtained about the functionalities, components, and associations of molecules in HSs (Clapp et al. 2005).

Applications of DOSY by Simpson et al. (2002) showed that operationally defined HAs are mixtures of proteinaceous-, carbohydrate-, and lignin-derived components, each of which independently diffuses, and hence are distinct molecules. These formed associations in the operationally defined humic mixture.

More-recent studies by Simpson et al. (2006) used liquid-state NMR on extracts 
in DMSO $+6 \% \mathrm{H}_{2} \mathrm{SO}_{4}$ following exhaustive extractions in a base and base + urea. This 'humin' material was shown to contain lipoproteins, carbohydrates, peptidoglycans, aliphatic hydrocarbons, and some altered lignin residues. These components were held in intimate associations with the clay, and the oxidized lignin was considered to be trapped in the component mixture.

\section{EMERGING CONCEPTS OF HUMIC STRUCTURES}

It is evident that the component molecules of HSs are still not unambiguously known. Considerable advances in identifying the organic structures have been made using NMR procedures, but so far the best identifications of the component molecules in the structures have been derived from identifying degradation products, and an awareness of the degradation mechanisms. We knew that 25 45\% of the components of soil HAs are aromatic, and that value may be higher in some instances, e.g., for samples from the $B_{h}$ horizons of some Podzols (Spodosols), and from soils containing significant amounts of char materials. Ten years ago, the consensus favored single-ring aromatic components with 3- to 5-ring substituents. That view has not changed, if the fused structures identified in pyrolysis are artifacts. However, fused ring structures are likely to be contained in HAs from soils where the burning of vegetation occurred, or where char materials were added to the soils. The hydrogen in 3 to 5 of the aromatic ring positions may be replaced by substituents consisting of hydroxyl, methoxyl, and aliphatic hydrocarbon structures. Some of these may be involved in linking aromatic structures. There is also evidence for aldehyde and ketones functional groups attached to some of the aromatic nuclei, for phenylpropane (3-carbon chains attached to the aromatic rings) units, and for hydroxyl and methoxyl substituents. The phenylpropane structures and hydroxy/methoxy substituents in the 3- and 4-, and in the 3-, 4-, and 5-ring positions would suggest origins in lignins, whereas the presence of these substituents in the 3- and 5-ring positions suggests origins in the skeletal structures or as metabolic products of microorganisms.

Fatty acids in degradation digests may be released from esters of phenols and other hydroxyl groups in the 'backbone' structures. Also these can arise from waxes and suberins and microbial products associated with HSs, and may contribute to the hydrophobic properties that have a role in the self-associations of HSs.

Titration data show that the acid groups in HSs provide a continuum of dissociable protons, and acid strengths ranging from strong to very weak. The strongest acids are carboxylic, and some are activated by neighboring groups. Phenolic hydroxyls also contribute to acidity, and these are most abundant in HA fractions. It would seem that their contribution to the total acidity is greatest in newly formed humic substances, especially in those with origins in the lignified components of plants. As oxidation takes place, the phenols are oxidized, and eventually carboxylic acids are formed. Some of the phenolic substituents can have enhanced acidity because of the influences of other substituents on the aromatic structures. Enols and other weakly dissocited groups also contribute to the charge characteristics under alkaline conditions.

The random coil model for solution conformations of HAs have served well for explaining interactions of chemicals with SOM components (Swift 1989). However, evidence in recent times suggests that molecular associations give false high-MW properties to HSs, and that the major components have values of 
$<2000$ Da. Numerous structures have been proposed for HSs during the course of the last few decades. In general, these were based on speculation, or on aspects of research that were in vogue at the time. Although it is not possible to give a definite structure for any of the major components of SOM, we are emerging from the world of "mystery and magic" where HSs are concerned, and there is real hope that soon there will be a realistic awareness of humic compositions and structures, and of the associations of molecules which give rise to the humic fractions. It is not necessary to know the exact structures in order to have a good understanding of the composition, or to be able to predict how the molecules will react with other species.

\section{LITERATURE CITED}

Aiken GR, McKnight DM, Wershaw RL, MacCarthy P. 1985. An introduction to humic substances in soil, sediment, and water. In: Aiken GR, MacCarthy P, Malcolm RL, Swift RS, editors. Humic substances in soil, sediment, and water. New York: Wiley. p 1-9.

Clapp CE, Hayes MHB. 1996. Isolation of humic substances from an agricultural soil using a sequential and exhaustive extraction process. In: Clapp CE, Hayes MHB, Senesi N, Griffith SM, editors. Humic substances and organic matter in soil and water environments. University of Minnesota, St. Paul, MN: International Humus Substance Society. p 3-11. Hayes MHB. 1985. Extraction of humic substances from soil. In: Aiken GR, MacCarthy P, Malcolm RL, Swift RS, editors. Humic substances in soil, sediment, and water. New York: Wiley. p 329-62.

Hayes MHB. 2006. Solvent systems for the isolation of organic components from soils. Soil Sci Soc Am J 70:986-94.

Hayes MHB, MacCarthy P, Malcolm RL,
Swift RS. 1989. The search for structure: setting the scene. In: Hayes MHB, MacCarthy P, Malcolm RL, Swift RS, editors. Humic substances II: In search of structure. Chichester, UK: Wiley. p 3-31.

Hayes MHB, Malcolm RL. 2001. Considerations of compositions and aspects of the structures of humic substances. In: Clapp CE, Hayes MHB, Senesi N, Bloom PR, Jardine PM, editors. Humic substances and chemical contaminants. Madison, WI: Soil Science Society of America. p 3-38.

Hayes MHB, Swift RS. 1978. The chemistry of soil organic colloids. In: Gredenland DJ, Hayes MHB, editors. The chemistry of soil constituents. Chichester, UK: Wiley. $p$ 179-320.

Hayes MHB, Swift RS. 1990. Genesis, isolation, composition and structures of soil humic substances. In: DeBoodt MF, Hayes MHB, Herbillon A, editors. Soil colloids and their associations in aggregates. New York: Plenum Press. p 245-305.

Hayes TM, Hayes MHB, Skjemstad JO, Swift RS, Malcolm RL. 1996. Isolation of humic substances from soil using aqueous extractants of different $\mathrm{pH}$ and $\mathrm{XAD}$ resins, and their characterization by ${ }^{13} \mathrm{C}-\mathrm{NMR}$. In: Clapp CE, Hayes MHB, Senesi N, Griffith SM, editors. Humic substances and organic matter in soil and water environments. Proceeding of $7^{\text {th }}$ International Conference, International Humus Substance Society. University of Minnesota, St. Paul, MN: International Humus Substance Society Press. p 13-24.

Senesi N, Loffredo E. 1999. The chemistry of soil organic matter. In: DL Sparks, editor. Soil physical chemistry. $2^{\text {nd }}$ ed. Boca Raton, FL: CRC Press. p 239-370.

Simpson AJ, Kingery WJ, Hayes MHB, Spraul M, Humpfer E, Dvortsak P, Kerssebaum R, Godejohann M, Hofmann M. 2002. Molecular structure and associations of humic substances in the terrestrial environment. 
Naturwissenschaften 89:84-8.

Simpson AJ, Song G, Smith E, Lam B, Novotony EH, Hayes MHB. 2007. Unraveling the structural components of soil humin using solution state nuclear magnetic resonance spectroscopy. Environ Sci Technol. 41: 876-83.

Stevenson FJ. 1994. Humus chemistry: genesis, composition, reactions. $2^{\text {nd }}$ ed. New York: Wiley.

Swift RS. 1996. Organic matter characterization. In: Sparks DL, editor. Methods of soil analysis. Part 3. Chemical methods. SSSA Book Series no. 5. Madison, WI: Soil science Society of America and American Society Agronomy. p 1011-69.

Tate RL. 1987. Soil organic matter: Biological and ecological effects. New York: John Wiley. $291 \mathrm{p}$.

Zech W, Senesi N, Guggenberger G, Kaiser K, Lehmann J, Miano TM, et al. 1997. Factors controlling humification and mineralization of soil organic matter in the tropics. Geoderma 79:117-61. 